Nigerian Journal of Technology (NIJOTECH)

Vol. 34 No. 4, October 2015, pp. 802 - $\mathbf{8 0 8}$

CopyrightC Faculty of Engineering,

University of Nigeria, Nsukka, ISSN: 0331-8443

www.nijotech.com

http://dx.doi.org/10.4314/njt.v34i4.19

\title{
QUANTIFICATION OF RAIN INDUCED ARTIFACTS ON DIGITAL SATELLITE TELEVISION RECEPTION
}

\author{
0. 0. Obiyemi ${ }^{1,}{ }^{*}$, T. S. Ibiyemi ${ }^{2}$, T. H. Ogunbeku ${ }^{3}$, A. Y. Abdulrahman ${ }^{4}$ and M. K. Adbulmajeed ${ }^{5}$ \\ 1DEPT. OF ELECTRICAL \& ELECTRONIC ENGINEERING, OSUN STATE UNIVERSITY, OSOGBO, OSUN STATE. NIGERIA. \\ 2,4 DEPT OF EleCtricAl \& EleCTRONICS ENGINEERING, UNIVERSITY OF ILORIN, ILORIN, KWARA STATE. NIGERIA \\ 3 Department of Physics, Osun STate University, Osogbo, Osun STATE. NIGERIA. \\ 5 King Fahd University of PETroleum and Minerals, Dhahran 34464, SAUDi ARABIA \\ E-mail addresses: 1 obiseye.obiyemi@uniosun.edu.ng, ${ }^{2}$ ibiyemits@yahoo.com, ${ }^{3}$ hezekiahogunbekun@gmail.com, \\ 4abdulrahmanyusuf35@gmail.com,5kbmajeed1@gmail.com
}

\begin{abstract}
The presence of artifacts on the high definition television (TV) content and the eventual loss of the digital TV signals to rain is still a major concern to satellite operators, digital satellite television (DSTV) and terrestrial television content providers. In this paper, the artifacts present in a typical DSTV signal is examined on a practical direct-tohome (DTH) link at Osun State University, Osogbo, Nigeria $\left(7.77^{\circ} \mathrm{N}, 4.60^{\circ} \mathrm{E}\right)$, received via EUTELSAT W4/W7 at 12.245 GHz. The degrading effect is assessed using a subjective experimental approach, which is based on the quantification of the artifacts ruining user's Quality of Experience (QoE) during rainfall events. Results indicate that the thunderstorm rainfall is accountable for the impairment, while pixilation was observed as a dominant artifact appearing before the loss and shortly at the recovery of the DSTV signal.
\end{abstract}

Keywords: digital satellite television, rain attenuation, digital artifacts, pixelation, rainfall rate

\section{INTRODUCTION}

With the implementation of the DVB-S2 standard, Digital Satellite Television (DSTV) promises to break the limits of television (TV) viewing experience mainly due to increased bitrate over the same satellite transponder bandwidth. However, the degrading impact of high-intensity rainfall events is still a major concern to radio scientists and engineers, particularly at frequencies beyond $10 \mathrm{GHz}$ [1-3]. The scattering, absorption and depolarization of the signal often distort vital features of the DSTV signals, thereby degrading the quality of the highly defined video and sound at reception.

Coincidentally, broadcast satellites are undeniably a crucial part of the terrestrial broadcast of the digital television, and the degrading rainfall effect is also experienced on most terrestrial, cable and mobile TV services. Hence, broadcast satellites serve as relay stations for digital TV content delivery over terrestrial links, where digital TV content is distributed to terrestrial TV operators for onward transmission to respective subscribers.
Digital artifacts such as frozen frames, pixelation, blue screen and blocking are commonly observed in distorted video frames. Other common DSTV artifacts that degrade the quality of the high definition digital content delivered via the DTH link include mosquito noise, edge flicker, jagged effects and blur $[4,5]$. All these phenomena adversely affect user's quality of experience (QoE).

The extent of signal distortion depends on a number of factors which include transmission power, frequency, ambient temperature, wind speed, polarisation, rainfall rate and rainfall droplet size $[1,6$, 7]. The last two factors are prominently macrostructural rainfall properties useful for rain attenuation prediction [1, 8-11]. Therefore, precipitation measurement logging either or both parameters for every rainfall event remains very useful for radio climatic studies. Rainfall events are generally made up of two constituent precipitation types; the convective and the stratiform [12]. Convective precipitation is typically characterized with high rainfall intensity $(\sim>20 \mathrm{~mm} / \mathrm{h})$, lasting over 
a short period of time over a little coverage area, and accompanied by showers and thunderstorms [13]. On the other hand, stratiform precipitation $(\sim<20$ $\mathrm{mm} / \mathrm{h}$ ) is characterized with widespread and low rain rates, lasting for relatively longer period of time. The stratiform rain event mainly accounts for drizzle and widespread rain[13, 14].

\section{RELATED WORK}

The effects of rainfall on video quality and the strength of the signal received on a practical earthspace link was investigated in [3], for a high-speed link based on the WINDS satellite using an Ultra Small Aperture Terminals (USAT). Similarly, a recent experimental investigation on rainfall effects on a digital DTH link in Nigeria [7] revealed that the digital television content is completely lost to the prevailing impact of rain at high rainfall intensity, typically around $64 \mathrm{~mm} / \mathrm{h}$. In a different experiment [15], the effect of network quality of service (QoS) on QoE was investigated on Hyper-Text Transfer Protocol (HTTP) video streaming, where subjective experiments were also carried out on a collection of videos distorted by a variety of application-relevant processes. In their work, distorted video frames were created using four different commonly encountered distortion types. Each video frame was assessed by 38 human subjects, and the difference mean opinion scores (DMOS) were recorded. The performance of several state-of-the-art, publicly available full-reference algorithms was also evaluated on the database. A statistical evaluation of the relative performance of these algorithms is also presented. In [5], a number of subjective experiments were conducted using typical streaming content, code cs, bitrates and network conditions. The two assessment methods used are the Single Stimulus Continuous Quality Evaluation (SSCQE) and Double Stimulus Impairment Scale (DSIS) methods.

In this paper, we investigate the degrading impacts of rain on a typical digital satellite television reception at Osun State University. The degrading effect is assessed using a subjective experimental approach, which is based on the quantification of the artifacts ruining user's QoE during rainfall events.

\section{MEASUREMENT SETUP}

The measurement setup comprises of the outdoor and indoor units, where the digital television content is concurrently monitored with the rainfall intensity. The measurement system is installed at the Department of Electrical and Electronic Engineering and the outdoor unit of this installation is at rooftop of the College of Science, Engineering and Technology building, Osun State University $\left(7.77^{\circ} \mathrm{N}, 4.60^{\circ} \mathrm{E}\right)$, Osogbo, Nigeria. In the outdoor unit, the Integrated Sensor Suit (ISS) of the electronic weather station (Davis Ventage Vue) is co-located with a $90 \mathrm{~cm}$ offset parabolic reflector, receiving digital television from Multichoice Africa via EUTELSATW4/W7 - geostationed at longitude $36^{\circ} \mathrm{E}$ for reception at 12.245 GHz. The low-noise block down converter (LNB) used is with a Noise Figure (NF) of $0.2 \mathrm{~dB}$; input frequency between 10.7 and $12.75 \mathrm{GHz}$ while the local oscillator frequency is $9.75 / 10.6 \mathrm{GHz}$.

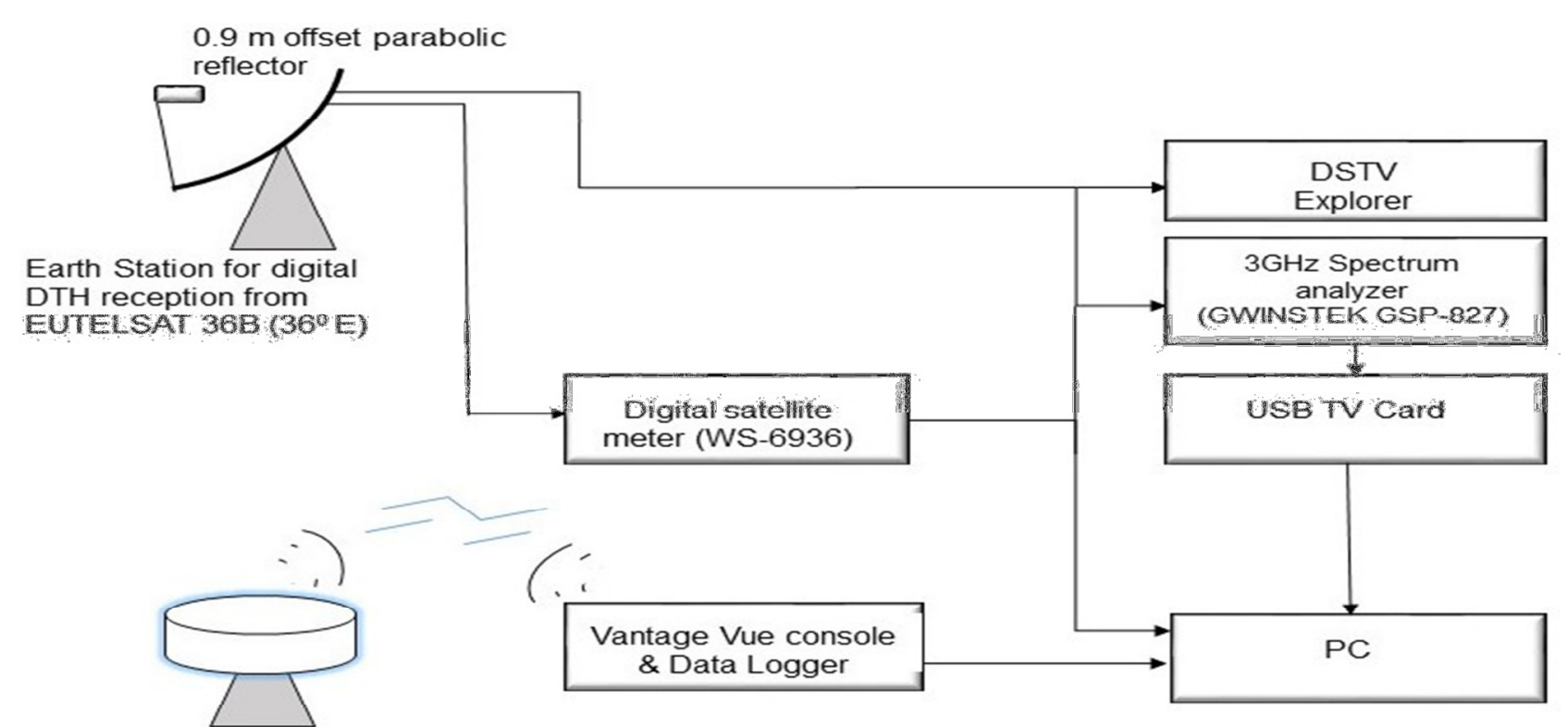

ISS for Vantage Vue Weather Station

Figure 1. The block diagram of the experimental setup 


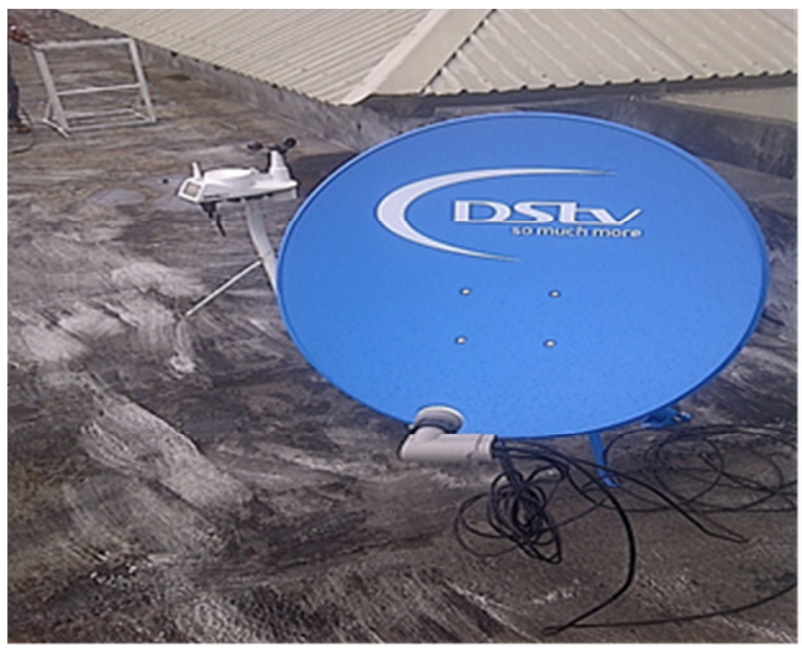

Figure 2. Outdoor unit of the measurement system

The indoor unit is made up of the digital TV decoder (DSTV Explorer) - recording the digital video signals during both rainy and clear sky events, a spectrum analyzer (GWINSTEK GPS-827), the indoor console of the weather station and a central computer unit for data collection. The block diagram of the measurement setup is presented in Figure 1, while Figures 2 and 3 show the outdoor and indoor units respectively.

The precipitation data was collected using a selfemptying tipping spoon (with a resolution of $0.2 \mathrm{~mm}$ per tip), which is part of the Integrated Sensor Suit (ISS). The accuracy of the gauge is $+1 \%$ at 1 litter $/ \mathrm{h}$ with a measuring range of a minimum of $2 \mathrm{~mm} / \mathrm{h}$ to a $400 \mathrm{~mm} / \mathrm{h}$. The gauge is accurate to within $2 \%$ up to $250 \mathrm{~mm} / \mathrm{h}$. The data logger scans the data at an interval of one second, integrated over 1 minute. The availability of the gauge is about $99.2 \%$. The $0.8 \%$ unavailability is due to system maintenance. The ISS also houses other sensors for monitoring parameters such as relative humidity, wind speed, wind direction, temperature among others. It serves as the outdoor unit, which employs frequency-spread spectrum technique to wirelessly connect with the indoor console [15].

\section{RESULT AND DISCUSSION}

From the precipitation data obtained from the installation at the rooftop (about $360 \mathrm{~m}$ above sea level) of the College of Science, Engineering and Technology (CSET) building at Osun state University, Osogbo, Nigeria $\left(7.76^{\circ} \mathrm{N}\right.$ and $\left.4.60^{\circ} \mathrm{E}\right)$, the point rainfall rates, $\mathrm{R}_{0.01}$ required for the prediction of raininduced attenuation over Osogbo was deduced from a 17-month observation using the electronic Davis Ventage Vue weather station. The cumulative rain rate

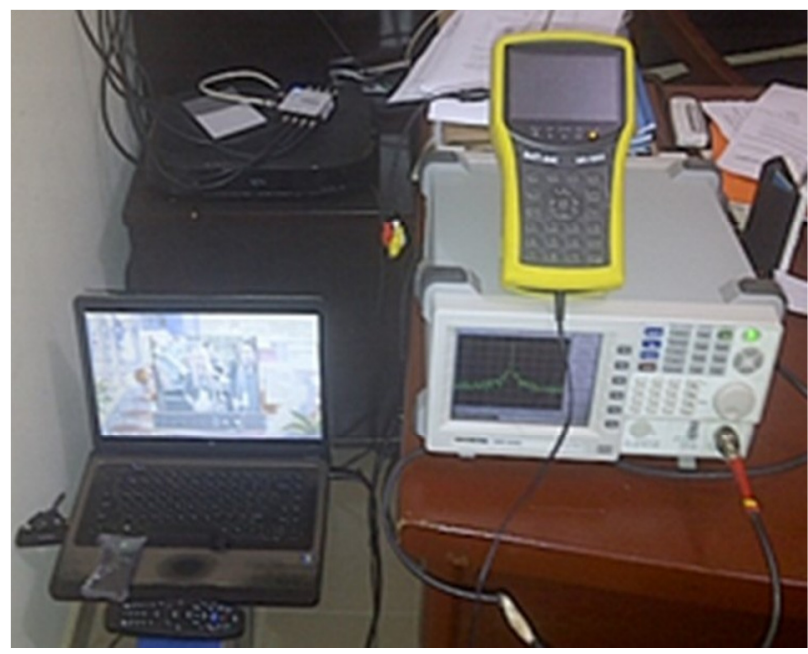

Figure 3. Indoor unit of the measurement system

distribution (CD) for the 17-month precipitation measurement is presented in Figure 4[16]. As shown, the rain rate exceeded at $0.01 \%$ of the time is 120 $\mathrm{mm} / \mathrm{h}$. This value agrees with predictions based on the ITU-R rainfall rate model, which confirms that Osogbo falls within the $\mathrm{P}$ zone of the ITU-R rain climatic zoning [17].

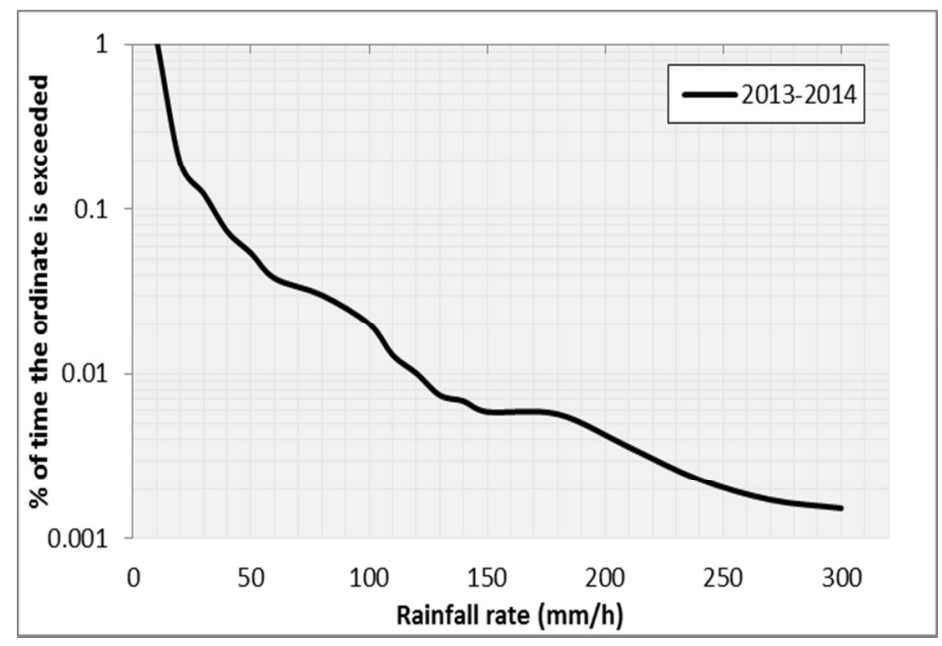

Figure 4: Cumulative Rain rate distribution for Osogbo, Osun State, Nigeria

On the quantification of the effect of rainfall intensity on the digital television content, signal outage occurred a number of times during typical rainfall events, especially for rainfall intensities exceeding 70 $\mathrm{mm} / \mathrm{h}$. This disruption was sustained until the rainfall intensity dropped significantly below this threshold. The observations presented were logged on the $1^{\text {st }}$ of July 2014 around 17:11 hours (GMT) during a highintensity rain event (thunderstorm), lasting for about one minute with a rainfall intensity of $135 \mathrm{~mm} / \mathrm{h}$. 


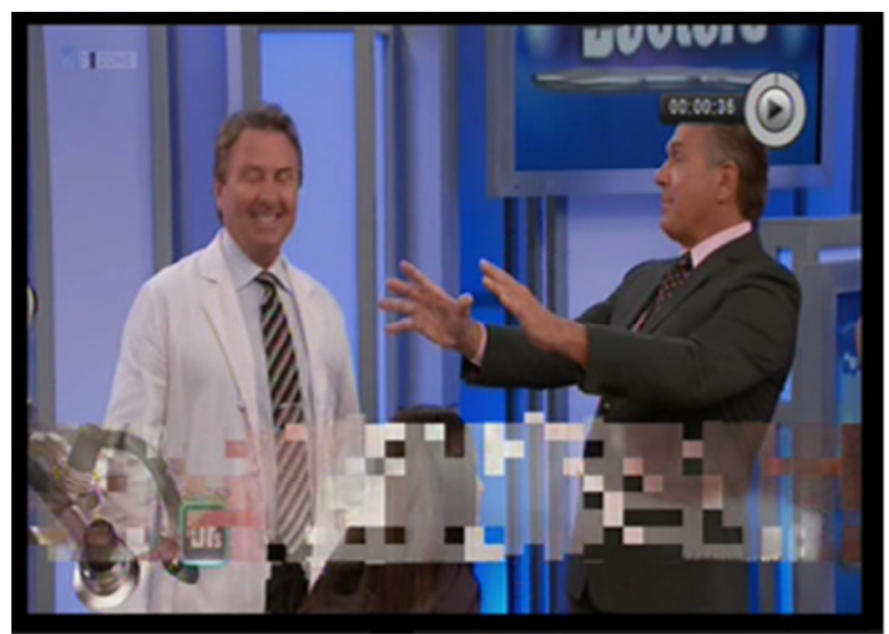

Figure 5.Recorded frame with pronounced pixelation

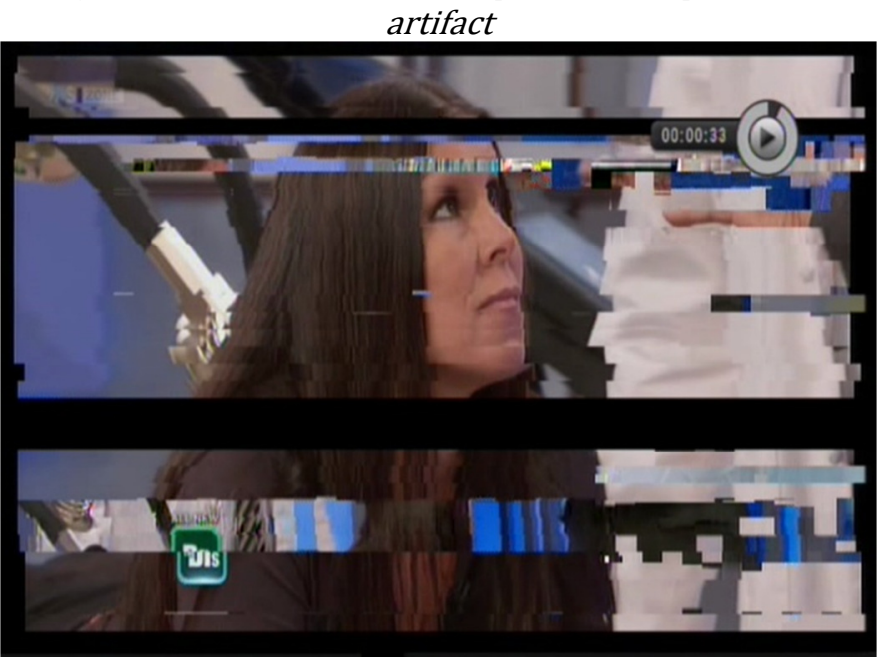

Figure 7.Recorded frame with increased artifacts

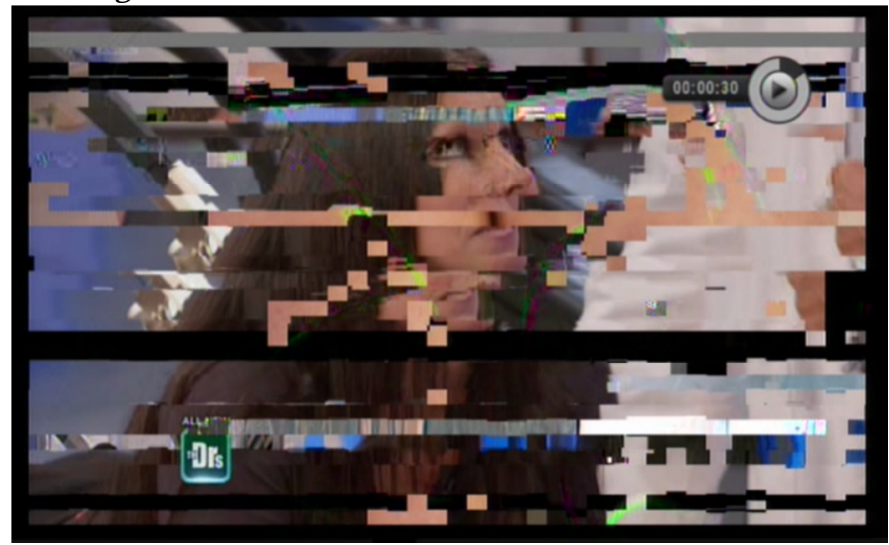

Figure 9. Recorded frame with pixelation, line-crawling, mouse-teeth, and blur artifacts

The recorded frames are presented as still images showing the level of degradation and the corresponding artifacts. It also reveals the transition from a high definition digital imagery to complete loss of the digital content - as induced by rain. This is as shown in Figures 5 to 11. Drawing inference from the still image in Figure 5, the digital image is affected by pixelation only at the lower portion of the frame. The other portion not affected by pixelation is however

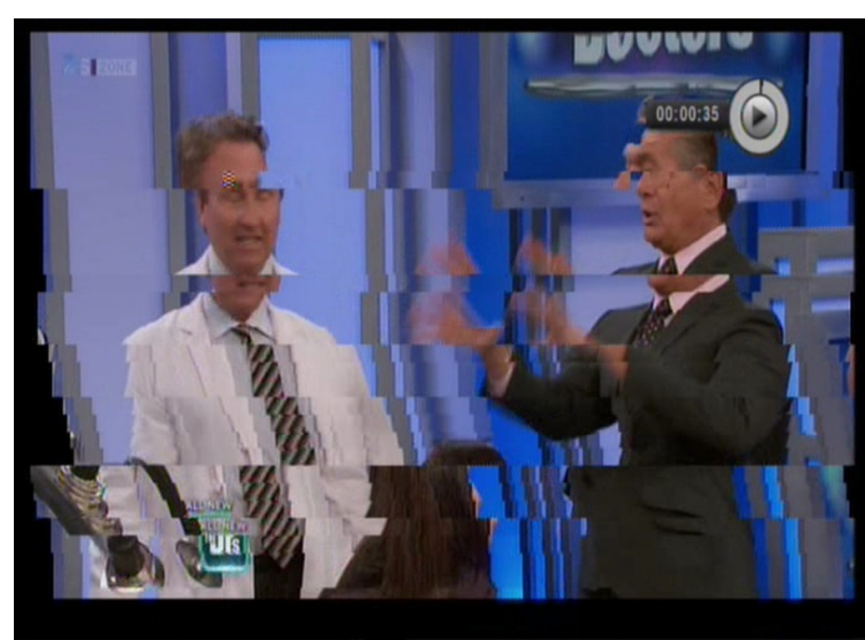

Figure 6.Recorded frame with multiple artifacts

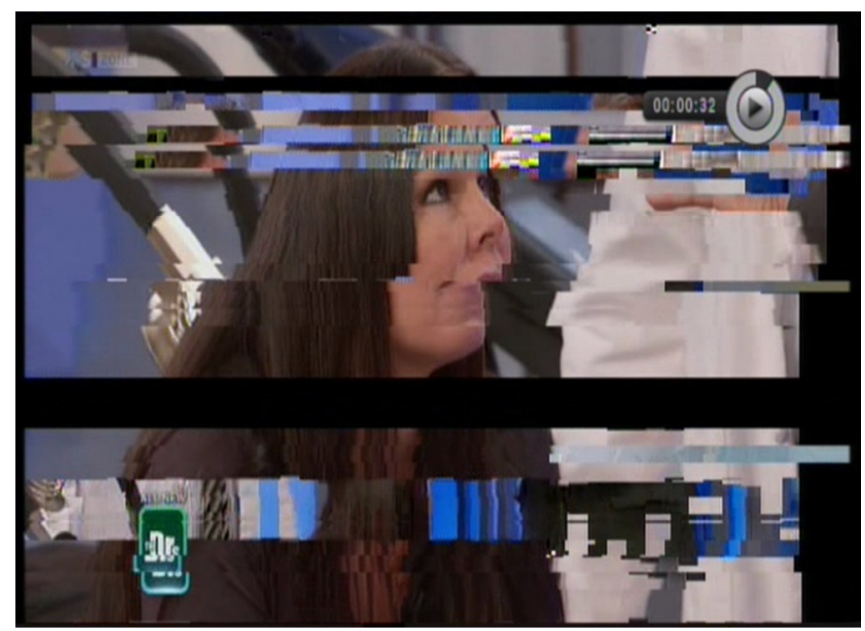

Figure 8.Recorded frame with more artifacts

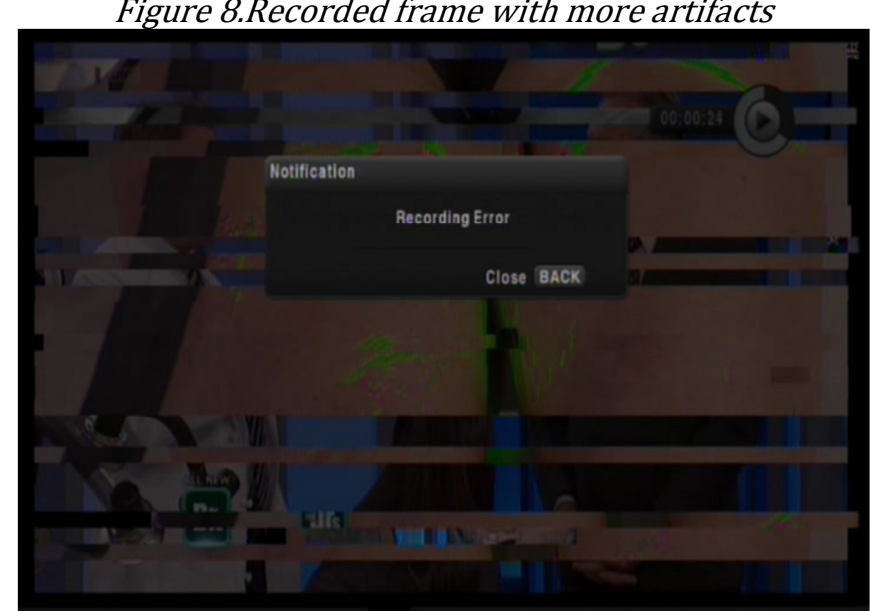

Figure 10. Recorded frame with artifact overlap

blurred. Line-crawling artifact is also present in the still image, especially around the hands of the character at the right. Figure 6 however records more digital television artifacts. Pixelation covers more area of the frame, while line-crawling can be noticed all over the still apart from the topmost portion. Mouseteeth artifact is also noticed around the edges of each character, although more pronounced in the left than 
the right portion, while all other part of the still is blurred.

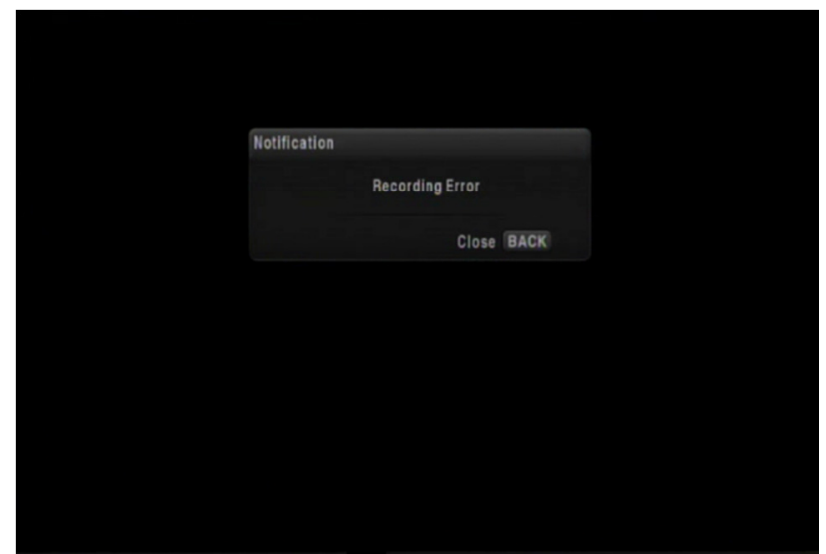

Figure 11. Recorded frame showing total signal loss to the prevailing rain event

Figure 7 shows a 'mimic' of total signal loss with a partial image loss at the middle and upper portion of the still, while pixelation is dominant at the upper and lower sections. Although not affecting the extreme top, line-crawling artifact is also observed at the center of the frame. The degrading effect of attenuation by rain is more pronounced in the image in Figure 8. Pixelation, line-crawling and mouse-teeth artifacts are obvious in the still. Partial image loss is also spotted while the extreme top of the still is now affected by pixelation and blur, rather than blur alone. This degrading effect is worsened in Figure 9 as overlapping is still observed, while partial image loss is also noticed in larger portions of the still image. Judging from the still in Figure 10, the effects recorded in Figure 9 indicates nearness to complete signal loss. An overlapping of artifacts and blank image is observed. The signal is completely lost in Figure 11 with a blank screen during the high intensity rainfall event.

From the above transition sequence, it can be observed that pixelation is the strongest and dominant artifact encountered as a result of rain attenuation. The inception of the attenuation of the received signal witnessed a gradual drop in the quality of the high definition digital television image, where other artifacts like line-crawling, mouse-teeth, blur and line-crawling were observed as artifacts, although other artifacts disappeared with time except pixelation. The observation of the partial image loss and the eventual loss of the signal to the prevailing influence of rain is still pronounced and this remains a major drawback to digital satellite television reception over the years.

\section{ON THE ANALYSIS OF IMAGE PIXELATION}

From our observation, pixilation appears to be the most dominant artifact. The level of degradation is hereby quantified based on a pixelation analysis using an audience-perception technique. Common measurements of video quality include Peak Signal-toNoise Ratio (PSNR), which is usually based on the Mean Squared Error (MSE) and the Structural Similarity (SSIM) Index. Although, image quality assessment requires a 'clean', 'unpixelated', image to serve as reference for the degree of pixilation occurring in subsequent images[18], obtaining reference snapshots from video frames not affected by pixilation artifacts was difficult, especially for the same time. An Audience-Perception (AP) approach was therefore employed for evaluating the image pixilation on the distorted frames. In this method, an AP score of values between 0 and 1 are allocated to the images. The value of this index corresponds to the ratio of the 'total area of degraded pixels having no attribute to the picture' to 'the total area of pixels in the picture'. The pictures were resized to a global 300 x 300 thus 90,000pixels. Regions of interest containing pixelated artifacts were selected by an observer and calculations were done using Matlab. An AP score of 0 represents an image without pixilation artifacts, while an AP score of 1 represents a total pixelation degradation of the image.

An image is more or less a matrix with values 0- 255 or normalized 0 - 1 in 2 dimensions. Since images have been resized to $300 \times 300$, the representation of the images analyzed is a matrix of size 300 rows and 300 columns as described mathematically in Equation (1).

$$
\text { Image }=\left[\begin{array}{ccc}
I_{1,1} & \cdots & I_{1, m} \\
\vdots & \ddots & \vdots \\
I_{n, 1} & \cdots & I_{n, m}
\end{array}\right]_{n, m=1,2 \ldots 300}
$$

The assumption that the whole image is not pixelated as there are still some visible regions of the scene by the observer. Thus the matrix for the pixelated image is of dimensions less than that of the full image. Thus it has a size less than 300 but greater than 0 .

$$
\text { Pixelated Image }=\left[\begin{array}{ccc}
I_{1,1} & \cdots & I_{1, m} \\
\vdots & \ddots & \vdots \\
I_{n, 1} & \cdots & I_{n, m}
\end{array}\right]_{1 \leq n, m<300}
$$

Total Area of Pixels in Image $=n_{\text {max }} \times m_{\text {image }}(3)$ AP score is the ratio of degraded pixels to total area of pixels in the image.

Vol. 34 No. 4, October 2015 


$$
\mathrm{AP}=\frac{\text { Area of Degraded Pixels }}{\text { Total Area of Pixels in Image }}
$$

Table 1: Results from the pixelation analysis

\begin{tabular}{llll}
\hline $\begin{array}{l}\text { Picture } \\
\text { Frame }\end{array}$ & Pixels & $\begin{array}{l}\text { Pixels Total } \\
\text { Area }\end{array}$ & $\begin{array}{l}\text { AP } \\
\text { Score }\end{array}$ \\
\hline Figure 5 & $3.0512 \mathrm{e}+04$ & 30512 & 0.33902 \\
Figure 6 & $3.6988 \mathrm{e}+04$ & 36988 & 0.41098 \\
Figure 7 & $6.5282 \mathrm{e}+04$ & 65,282 & 0.72536 \\
Figure 8 & $5.3702 \mathrm{e}+04$ & 65805.3 & 0.73117 \\
Figure 9 & $2.7908 \mathrm{e}+04$ & 88518 & 0.98353 \\
Figure 10 & $8.9999 \mathrm{e}+04$ & 90000 & 1 \\
\hline
\end{tabular}

Results confirm that pixelation is present in the frames analyzed. Although mild in Figure 5 with an AP score of 0.33902 , Figure $6,7,8$, and 9 records 0.41098 , $0.72536,0.73117$ and 0.98353 respectively, while Figure 10 presents a completely degraded image with an AP score of 1.

The degrading effect of high rainfall events on DSTV reception is not only evident on the visual component of the signal (in terms of artifacts displayed and total loss) but also on the audio component of the digital signal. From the same transition sequence, it was noticed that the audio component was present at the beginning and was lost as the effect of rain worsened. Although there are few fractions of the time when the audio component was present but only surfaced as noise.

\section{CONCLUSION}

The results obtained from the experimental assessment of the degrading impact of rain on the QoE of DSTV subscribers in Osogbo, South Western Nigeria has been presented over a practical digital DTH link, for reception via the new DSTV Explorer. It has been observed that as signal approaches outage during high rainfall event, a number of digital television artifacts become more pronounced on the visual component of the signal, while the audio is also lost as degradation worsens. The recovery time is dependent on the duration of thunderstorm rain, usually lasting for a short period of the time for a typical rainfall event. The results indicate that pixelation remains a pronounced artifact; hence, the level of degradation was quantified using the AP technique for the rainimpaired digital TV reception. There is the need to optimize reception by employing a mitigation technique that can protect the integrity of the digital television. This is particularly important since other terrestrial broadcast platforms depend on the satellite feed for onward broadcast to their respective subscribers within the coverage areas.

\section{REFERENCES}

[1] G. O. Ajayi, S. Feng, S. M. Radicella, and B. M. Reddy (Eds.), Handbook on radiopropagation related to satellite communications in tropical and subtropical countries: International Centre for Theoretical Physics, 1996.

[2] R. K. Crane, Electromagnetic wave propagation through rain: Wiley New York, 1996.

[3] Y. H. Lee and S. Winkler, "Effects of rain attenuation on satellite video transmission," in Vehicular Technology Conference (VTC Spring), 2011 IEEE 73rd, 2011, pp. 1-5.

[4] S.-F. Lin, Y.-L. Chang, and L.-G. Chen, "Motion Adaptive Interpolation with Horizontal Motion Detection for De-interlacing," IEEE Transactions on Consumer Electronics, vol. 49, 2003.

[5] S. Winkler and R. Campos, "Video quality evaluation for Internet streaming applications," in Electronic Imaging 2003, 2003, pp. 104-115.

[6] S. Das, A. Maitra, and A. K. Shukla, "Rain attenuation modeling in the $10-100 \mathrm{GHz}$ frequency using drop size distributions for different climatic zones in tropical India," Prog. Electromagn. Res., vol. 25, pp. 211-224, 2010.

[7] 0. O. Obiyemi, T. J. Afullo, and T. S. Ibiyemi, "Evaluation of Rain Degraded Digital Satellite Television Reception in Tropical Regions," Int. Journal of Scientific \& Engineering Research. Vol. 4. No. 12., vol. 4, pp. 790-799, 2013.

[8] A. A. Alonge and T. J. Afullo, "Regime analysis of rainfall drop-size distribution models for microwave terrestrial networks," IET microwaves, antennas \& propagation, vol. 6, pp. 393-403, 2012.

[9] A. Y. Abdulrahman, T. A. Rahman, I. M. Rafiqul, B. J. Olufeagba, T. A. Abdulrahman, J. Akanni, et al., "Investigation of the Unified Rain Attenuation Prediction Method With Data From Tropical Climates," Antennas and Wireless Propagation Letters, IEEE, vol. 13, pp. 1108-1111, 2014.

[10] J. S. Ojo and P. A. Owolawi, "Development of oneminute rain-rate and rain-attenuation contour maps for satellite propagation system planning in a subtropical country: South Africa," Advances in Space Research, vol. 54, pp. 1487-1501, 10/15/ 2014.

[11] 0. O. Obiyemi, T. S. Ibiyemi, and S. O. Akande, "Rainfall Variability and Impact on Communication Infrastructure in Nigeria," Journal of Telecommunications, vol. 25, pp. 6-11, 2014.

[12] A. Nordila, J. Jestin, and C. Siti Khadijah, "Analysis of Convective Structures using Meteorological Radar 
Data and Surface Data," International Journal of Engineering, vol. 1, pp. 2305-8269, 2012.

[13] A. A. Alonge and T. J. O. Afullo, "Rainfall Microstructural Analysis for Microwave Link Networks: Comparison at Equatorial and Subtropical Africa," Progress In Electromagnetics Research B, vol. 59, pp. 45-58, 2014.

[14] R. A. Houze Jr, "Stratiform precipitation in regions of convection: A meteorological paradox?," Bulletin of the American Meteorological Society, vol. 78, pp. 2179-2196, 1997.

[15] 0. O. Obiyemi, J. S. Ojo, and T. S. Ibiyemi, "Performance Analysis of Rain Rate Models for Microwave Propagation Designs Over Tropical
Climate," Progress In Electromagnetics Research M, vol. 39, pp. 115-122, 2014.

[16] 0. O. Obiyemi, O. Adetan, and T. S. Ibiyemi, "Recent update on one-minute rainfall rate measurements for microwave applications in Nigeria," International Journal of Wireless Communications and Mobile Computing, vol. 3, pp. 33-39, 2015.

[17] I. T. U. Radiowave Propagation Series, "Characteristics of precipitation for propagation modelling," in Recommendation ITU-R P.837-6, ed: ITU-R, Geneva, 2012.

[18] Z. Wang and A. C. Bovik, "A universal image quality index," Signal Processing Letters, IEEE, vol. 9, pp. 81$84,2002$. 